\title{
Cerâmicas avançadas no processo de retificação cilíndrica externa de mergulho com rebolos diamantados com a técnica da mímima quantidade de lubrificação e refrigeração otimizada
}

\section{(Advanced ceramics in the external cylindrical plunge grinding using the technique of minimum quantity of lubrication and the technique of optimized refrigeration with diamond wheels)}

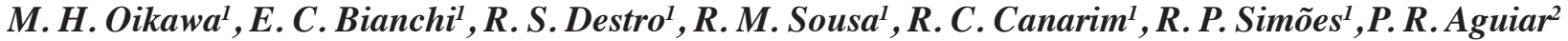 \\ ${ }^{I}$ Departamento de Engenharia Mecânica, ${ }^{2}$ Departamento de Engenharia Elétrica, Universidade Estadual \\ Paulista - UNESP, Campus de Bauru, Av. Luiz Edmundo Carrijo Coube, s/n, C.P. 473, Bauru, SP 17033-360 \\ rafael@fc.unesp.br,aguiarpr@feb.unesp.br
}

\begin{abstract}
Resumo
Os materiais cerâmicos têm muitas vantagens em relação a outros materiais, entre elas, três principais: capacidade de operação em altas temperaturas, alta dureza e alta resistência ao desgaste. Por essa razão, são aptos a serem usados em situações que exigem pouco desgaste, tanto em temperatura ambiente quanto em temperaturas elevadas. Estas propriedades fizeram as cerâmicas avançadas terem uma importante parte na utilização em aplicações na indústria nas últimas décadas. Porém, o custo agregado ao acabamento da peça ainda é muito alto. Esse acabamento geralmente é feito pelo processo de retificação, único processo economicamente viável que produz superfícies de elevada qualidade e precisão geométrica. As empresas desse modo vêm buscando a otimização no processo de retificação de cerâmicas, explorando outras técnicas de lubrificação. Assim, este projeto pretendeu explorar a otimização do método de lubrificação na retificação cilíndrica externa de mergulho com o método da mínima quantidade de lubrificação (MQL) e refrigeração otimizada. Foram utilizadas três métodos de refrigeração, o convencional o MQL e a refrigeração otimizada, com três avanços de corte para cada caso. Foram analisadas como variáveis de saída a relação G, rugosidade e circularidade. Dos resultados obtidos, podese concluir que a refrigeração otimizada é a que apresenta os melhores resultados, sendo esta uma alternativa viável de melhora do processo. O MQL apresentou resultados insatisfatórios em comparação aos outros dois métodos, porém, ainda aceitáveis em alguns processos de retificação. Considerando a dificuldade e altos custos de descarte do fluido de corte devido às rígidas leis ambientais, $o$ MQL vem como uma forte tendência neste tipo de processo.

Palavras-chave: cerâmicas avançadas, rebolos diamantados, retificação cilíndrica externa, MQL, refrigeração otimizada.
\end{abstract}

Abstract

Ceramic materials have many advantages over other materials, including three main: capability of operating at high temperatures, high hardness and high wear resistance. For this reason they are able to be used in situations that require little wear, both at ambient temperature or at elevated temperatures. These properties have made the advanced ceramics an important part in industry applications in recent decades. However, the aggregated cost in the piece finishing is still very high. This finish is usually done by the grinding process, the only economically viable process that produces pieces with high surface quality and geometric precision. The companies are then looking for optimizing the grinding process exploring other forms of lubrication. Thus, this project sought to explore the optimization of the method of lubrication in the cylindrical grinding with the technique of minimum quantity of lubrication $(M Q L)$ and optimized cooling. Three methods of cooling were used, the conventional, the MQL and the optimized cooling, with three speeds of depth in each case. The output variables G Ratio, roughness and circularity errors were analyzed. The analysis shows that the optimal cooling gives the best results, being a viable alternative to improve the process. The MQL showed unsatisfactory results in comparison to the other two methods, but still acceptable in some cases of grinding process. Considering the difficulty and high cost of disposal of cutting fluid due to the strict environmental laws, the MQL comes as a strong trend in this type of process.

Keywords: advanced ceramics, diamond wheels, external cylindrical grinding, MQL, optimized cooling.

\section{INTRODUÇÃO}

A indústria de cerâmica brasileira tem grande importância para o país, sendo que este segmento responde por aproximadamente $1 \%$ do Produto Interno Bruto [1]. Apesar de suas atrativas características de dureza e resistência ao desgaste, ainda se tem um alto custo agregado relativo ao acabamento da peça, quase sempre feito pelo processo de retificação. A retificação é praticamente o único processo economicamente viável para a usinagem de materiais cerâmicos após a sinterização, a fim de obter superfícies de elevada qualidade e precisão geométrica. Na fabricação de 
cerâmicas o custo com o acabamento, devido principalmente ao processo de retificação, é responsável por $50 \%$ do custo total da fabricação [2]. Não diferente da indústria metal mecânica, a retificação em cerâmicas é feita com usos de fluidos de corte. A função específica do fluido de corte no processo de retificação é a de proporcionar a lubrificação, (reduzindo o atrito da ferramenta com a peça), refrigeração, (removendo o calor gerado pelo atrito), remoção do cavaco gerado pelo processo e proteção das partes metálicas contra a corrosão. Ainda se tem um alto custo no uso de fluido de cortes. Estima-se que em um sistema de custos envolvendo as despesas gerais de produção e em particular, as despesas com fluidos de corte representa aproximadamente $17 \%$ do custo total de produção [3]. Além disso, devido à atual preocupação com o meio ambiente, os fluidos de corte ganharam uma atenção especial, devido ao seu alto poder de contaminação. Há, hoje em dia, leis que regem o uso e descarte desses fluidos nas indústrias e em qualquer ramo do setor de usinagem. Deste modo, este trabalho vem a explorar diferentes métodos lubrificação na retificação cilíndrica externa de mergulho com rebolos diamantados em cerâmicas avançadas, com a técnica do MQL (mínima quantidade de lubrificação) e a técnica da refrigeração otimizada, em comparação com a refrigeração convencional, analisando variáveis de saída de qualidade da peça como rugosidade, circularidade, microestrutura através de uma análise de microscopia eletrônica de varredura assim como variáveis de saída de desempenho do rebolo através da variável relação $\mathrm{G}$.

\section{Cerâmicas Avançadas}

O número de peças feitas com material cerâmico tem crescido gradualmente no campo da engenharia mecânica nos últimos tempos. Esta cerâmica usada em pecas mecânicas, denominada "cerâmica avançada", é diferente da tradicional e conhecida cerâmica. Elas têm vantagens em relação a outros materiais, devido, principalmente, a três características principais: alta dureza e alta resistência ao desgaste e capacidade de operação em altas temperaturas. Um exemplo de utilização são em motores e turbinas de gás, que contém peças que podem suportar altas temperaturas $\left(2000^{\circ} \mathrm{C}\right)$, ainda com alta resistência ao desgaste e segurança [4].

As cerâmicas são divididas geralmente em dois grupos principais, as cerâmicas óxidas e as não-óxidas. As ligações atômicas e as estruturas cristalinas desses materiais governam suas propriedades. As estruturas cristalinas dos materiais cerâmicos têm uma estrutura pouco simétrica comparada à estrutura dos metais, que são altamente simétricos. As estruturas cristalinas são formadas a partir de ligações covalentes, ligações iônicas e combinações de ambos. A relação de ligações covalentes em relação às ligações iônicas difere de 4:6 $\left(\mathrm{Al}_{2} \mathrm{O}_{3}\right.$ e cerâmicas óxidas) a 9:1 ( $\mathrm{SiC}$ e cerâmicas não-óxidas). As diferenças no tipo de ligação atômica são responsáveis pelas diferenças de dureza e módulo Young dos materiais cerâmicos. As cerâmicas com ligações covalentes são geralmente de alta dureza, rígidas e tem uma alta temperatura de fusão [5]. Como a estrutura cristalina da cerâmica é menos simétrica que a estrutura dos metais, mesmo o aumento de temperatura próximo ao ponto de fusão não resulta na ativação de mais do que dois ou três sistemas de deslizamento de discordâncias. Assim, há pouca deformação plástica e a elevada dureza persiste mesmo em altas temperaturas, ao contrário dos metais [6]. Um fato em comum desses materiais, é que a última camada de elétrons desses materiais está completa. Dessa forma, por causa da ausência de elétrons livres, as cerâmicas são pouco reativas e são isolantes elétricos. Uma visão mais geral das cerâmicas óxidas e não-óxidas com suas características físicas e mecânicas pode ser vista na Tabela I [4]:

De acordo com a análise da tabela desse autor, pode-se notar que as densidades das cerâmicas são muito menores que as dos aços, desse modo, as distâncias interatômicas são grandes, e a densidade dos elétrons é pequena. Ligações covalentes precisam de uma grande energia de ligação, $\left(1,1 \times 10^{-17} \mathrm{~J}\right.$ atom $\left.{ }^{-1}\right)$, que é cerca de 1000 vezes maior que as ligações metálicas $\left(1,5 \times 10^{-20} \mathrm{Jatom}^{-1}\right)$. Em muitas estruturas, a densidade dos deslocamentos é pequena e sua

Tabela I - Características físicas e mecânicas de algumas cerâmicas avançadas [4].

[Table I - Physical and mechanical properties of some advanced ceramics [4].]

\begin{tabular}{cccccccc}
\hline & $\begin{array}{c}\text { Densidade } \\
\left(\mathrm{g} / \mathrm{cm}^{3}\right)\end{array}$ & $\begin{array}{c}\text { Dureza } \\
\text { Vickers } \\
(\mathrm{HV})\end{array}$ & $\begin{array}{c}\text { Módulo de } \\
\text { Elasticidade } \mathrm{E} \\
(\mathrm{GPa})\end{array}$ & $\begin{array}{c}\text { Resistência à } \\
\text { Fratura } \\
\mathrm{K}_{\mathrm{lc}}(\mathrm{MPa} \sqrt{\mathrm{m}})\end{array}$ & $\begin{array}{c}\text { Resistência à } \\
\text { Flexão } \\
(\mathrm{MPa})\end{array}$ & $\begin{array}{c}\text { Condutividade } \\
\text { Térmica } \\
\left(\mathrm{W}_{\mathrm{m}} \mathrm{mk}^{-1}\right)\end{array}$ & $\begin{array}{c}\text { Resistência } \\
\text { Mecânica } \\
\left(\mathrm{N} \cdot \mathrm{mm}^{-1}\right)\end{array}$ \\
\hline $\mathrm{Al}_{2} \mathrm{O}_{3}$ & $3,8 \ldots 4,2$ & 16,5 & 344 & 4 & 304 & 25 & 360 \\
$\mathrm{ZrO}_{2}$ & 5,9 & 13 & 206 & 5 & 980 & 28 & 420 \\
$\mathrm{SiC}$ & $3,1 \ldots 3,2$ & 25 & 392 & 3,6 & 490 & 59 & 700 \\
$\mathrm{~B}_{4} \mathrm{C}$ & 2,5 & 26 & 300 & 7,5 & 700 & 29 & 400 \\
$\mathrm{SiN}_{4} \mathrm{HPSN}$ & 3,2 & 15 & 294 & 6 & 588 & 30 & 690 \\
$\mathrm{SiN}_{4} \mathrm{RBSN}$ & 2,5 & 17 & 345 & 6 & 750 & 17 & 215 \\
$\mathrm{C} 45$ & 7,8 & - & 210 & 120 & & 50 & 600 \\
\hline
\end{tabular}


mobilidade prejudicada, aumentando assim, os valores de dureza $(H V)$ e extrema rigidez. A rigidez é também indicada pelo valor do módulo de Young, mas é mais perceptível se o quociente $E / H V$ é comparado entre as cerâmicas e os aços. No caso de um material altamente dúctil, o valor $E$ / $H V$ é alto, cerca de 250 , diferente do caso de um material altamente frágil, que é cerca de somente 20. A resistência à fratura $\mathrm{K}_{\mathrm{lc}}$, ou a resistência à flexão são fatores também associados diretamente à rigidez e fragilidade [7]. A cerâmica em geral é frágil e não pode suportar as grandes tensões internas induzidas por expansões térmicas. Durante o processo de sinterização, há um "encolhimento" do material que não pode ser evitado. Conseqüentemente é necessário um processo de manufatura do material a fim de conseguir a forma e a precisão necessária para o componente [5]. A retificação é a mais favorável operação de acabamento dos materiais cerâmicos [8]. Pelas características do material, é evidente que o processo de remoção no material no caso da retificação em cerâmicas difere consideravelmente da teoria da retificação clássica. No primeiro caso, há o chamado "processo de remoção dúctill, onde a remoção do cavaco é feita por uma mudança elasto-plástica. Já no chamado "processo de remoção frágil" da retificação em cerâmicas, o material removido da cerâmica é retirado por um processo de trinca, separação e remoção do material [4].

Um estudo sobre a formação de trincas baseada no modelo de identação foi feito, usando uma esfera de pequeno diâmetro como identador. As seis fases de formação das trincas podem ser vistas na Fig. 1 [7]:
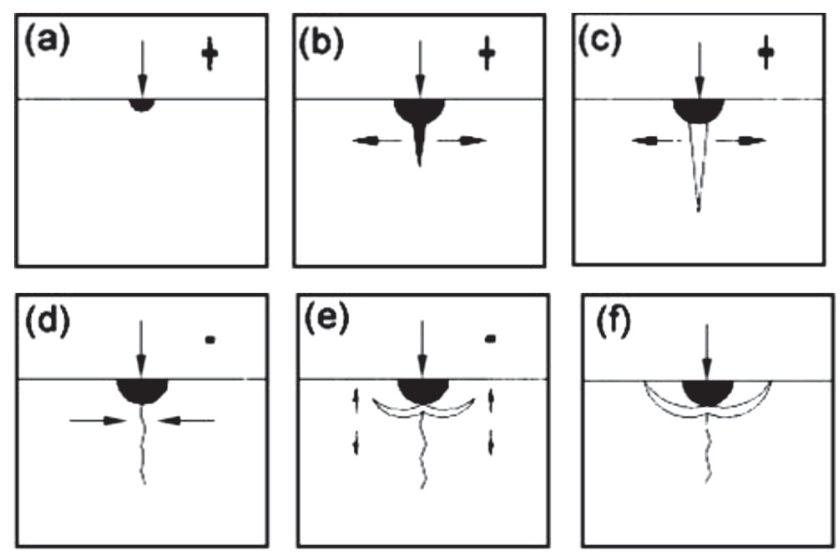

Figura 1: Estágios de formação das trincas através da indentação [7]. [Figure 1: Stages of crack formation under point indentation [7].]

Inicialmente, uma zona plástica de pequeno diâmetro é desenvolvida próxima à superfície (Fig. 1a). Em seguida, uma pequena trinca longitudinal (trinca média) iniciase devido ao campo de tensão desenvolvido (Fig. 1b). A trinca se propaga à medida que a indentação prossegue e aumenta de tamanho (Fig. 1c). Um decréscimo da carga resulta na redução do tamanho ou no fechamento da trinca longitudinal devido às tensões de compressão (Fig. 1d). A redução subseqüente da carga promove a formação de trincas transversais devido às tensões laterais (Fig. 1e).
Após a liberação da carga, devido ao campo de tensão residual desenvolvido, o tamanho da trinca lateral aumenta, conduzindo à separação do material na forma de cavacos (Fig. 1f). Os mesmos autores idealizaram ainda um modelo das trincas induzidas em função da indentação, conforme pode ser visto na Fig. 2 .

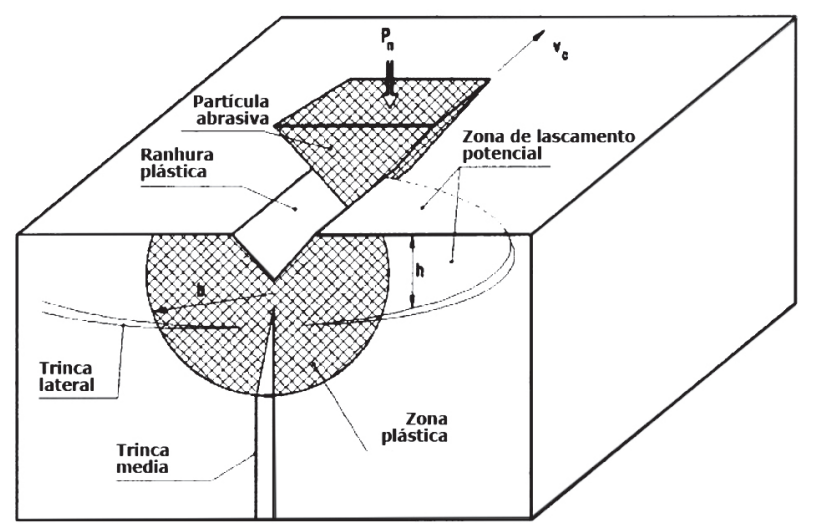

Figura 2: Zona plástica e formação das trincas médias/radiais e laterais devido ao riscamento por um grão abrasivo [7].

[Figure 2: Plastic zone and crack formation due to scratching by an abrasive grain [7].]

É preciso estar atento às taxas de avanços, pois os movimentos dos grãos abrasivos provocam um lascamento adicional que provoca um aumento na taxa de avanço de corte, conforme mostra a Fig. 3 [4].

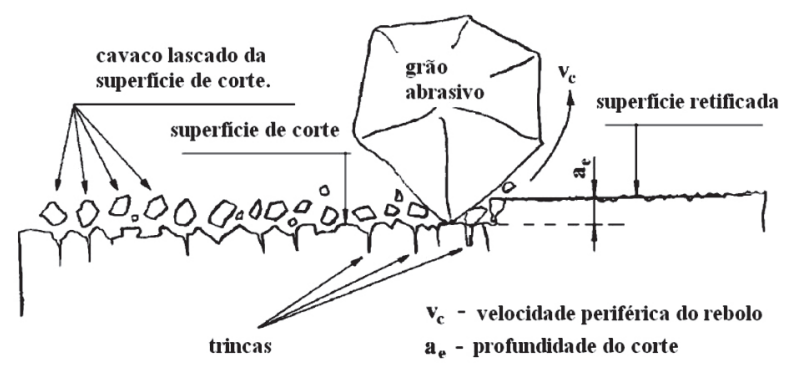

Figura 3: Modelo de formação do cavaco na retificação em cerâmicas [4].

[Figure 3: Model of chip formation in grinding of advanced ceramics [4].]

O mecanismo de remoção de material na retificação de cerâmicas depende do tamanho e da densidade de defeitos tais como falhas, trincas e o tamanho do campo tensionado. Segundo os autores, quando a região onde é aplicada a tensão é menor que o tamanho do defeito, o material é removido principalmente por deformação plástica. Caso contrário, o modo frágil é predominante [5].

\section{Espessura equivalente de corte $h_{e q}$}

A espessura da camada de material removida pelo rebolo 
numa volta completa denomina-se de espessura equivalente de corte $h_{e q}$, e é um parâmetro que permite quantificar uma condição de trabalho, sendo ainda definido como a relação entre a taxa de remoção específica do material $Q_{w}{ }^{\text {' }}$ e a velocidade de corte [9]. Desta forma, a espessura equivalente de corte para o processo de retificação cilíndrica externa pode ser representada pela equação A [10].

$$
h_{e q}=\frac{Q_{w}{ }^{\prime}}{V_{s}}=\frac{\pi \cdot d_{w} \cdot V_{f}}{60 \cdot 1000 \cdot V_{s}}
$$

A espessura equivalente de corte está diretamente relacionada com o comportamento do processo de retificação em função das variáveis envolvidas como: forças de corte, rugosidade, vida da ferramenta etc. [11]. Um aumento do $h_{e q}$ reflete no respectivo aumento das forças de corte, rugosidade e diminuição da vida do rebolo. Deste modo, busca-se sempre utilizar rebolos cujas ligas suportem elevadas rotações de trabalho a fim de se melhorar a rugosidade, aumentar a vida útil da ferramenta e diminuir os esforços de corte [12].

\section{Relação $G(G)$}

O desempenho de um rebolo pode ser avaliado através da relação $\mathbf{G}$ expressa na equação $\mathrm{B}$. Ela é definida como sendo a relação entre volume de metal removido $Z_{W}$ pelo volume de rebolo gasto $Z_{S}$ [5]:

$$
\mathrm{G}=\frac{\mathrm{Z}_{\mathrm{w}}}{\mathrm{Z}_{\mathrm{s}}}=\frac{\mathrm{a} \cdot \mathrm{V}_{\mathrm{w}} \cdot \mathrm{t}}{\pi \cdot \mathrm{D}_{\mathrm{S}} \delta}
$$

na qual $t=$ tempo de retificação e $\delta=$ desgaste radial do rebolo. O aumento da velocidade de corte contribui para manter a força efetiva em cada grão abrasivo abaixo do limite para arrancar o diamante da liga. Desta forma, o desgaste ocorre somente pela abrasão do diamante, maximizando a relação G [5].

\section{A técnica da mínima quantidade de lubrificação}

A técnica de mínima quantidade de lubrificação consiste numa mistura de óleo e ar comprimido, que formando uma névoa, é aplicada na região do corte, no lugar da convencional inundação de fluidos de corte, miscíveis ou imiscíveis em água [13]. Os sistemas de Mínima Quantidade de Lubrificação podem ser classificados de três formas distintas. A primeira delas consiste no sistema de pulverização de baixa pressão, em que o refrigerante é aspirado por uma corrente de ar e levado até a superfície. Estes sistemas apresentam um fluxo volumétrico de refrigerante entre 0,5 a $10 \mathrm{~L} / \mathrm{h}$. O segundo modelo utiliza bombas dosadoras com alimentação pulsatória de uma quantidade definida de lubrificante até a superfície sem a presença de um fluxo de ar comprimido. Estes sistemas são utilizados em processos intermitentes, com taxas de fluxo definidas entre 0,1 e $1 \mathrm{~mL}$ por ciclo, podendo atingir 260 ciclos por minuto. O terceiro e o mais empregado sistema de Mínima Quantidade de Lubrificação é o de pressão, que será utilizada neste trabalho, em que o refrigerante é bombeado através de uma tubulação distinta da do ar comprimido. Somente no bocal este refrigerante é misturado ao fluxo de ar e, então direcionado a interface de contato peça-ferramenta. Este modelo é bastante interessante pelo fato de permitir um ajuste independente das vazões de ar e de lubrificante. O consumo de óleo neste método é reduzido, definido entre 10 e $100 \mathrm{~mL} / \mathrm{h}$, já que o mesmo conta com o desempenho refrigerante do ar comprimido. Outro aspecto positivo deste sistema se concentra no fato da mistura coaxial de refrigerante e ar no bocal previnir em grande escala a nebulosidade [14].

A Fig. 4 mostra, esquematicamente, um sistema de Mínima Quantidade de Lubrificação baseado no principio de pressão (que será usado neste trabalho), porém representado para a usinagem com uma ferramenta de geometria definida [13].

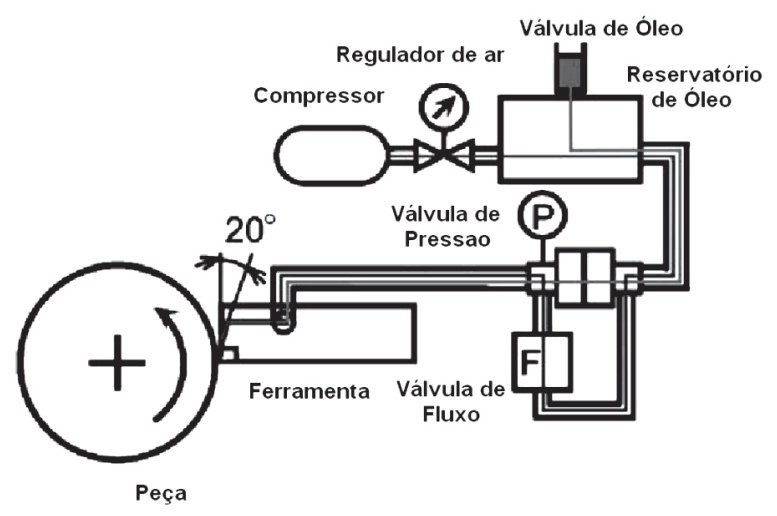

Figura 4: Modelo esquemático de um Sistema de Mínima Quantidade de Lubrificação por pressão para uma ferramenta de geometria definida [17].

[Figure 4: Schematic model of a Minimum Quantity of Lubrication system by pressure for defined geometry tool [17].]

Como os sistemas de Mínima Quantidade de Lubrificação requerem um espaço muito pequeno para instalação, ele pode ser fixado em diversas posições. Deste modo, o sistema de MQL torna-se flexível podendo ser aplicado tanto na retificação quanto em outros processos de corte [14]. Existem muitas vantagens da utilização da MQL se comparado com a refrigeração convencional. Dentre elas, as principais são a redução da potência de retificação e energia específica, além da melhora da qualidade superficial e do menor desgaste do rebolo. Com relação aos fluidos convencionais, os resultados com MQL para retificação de superfícies são melhores com óleo de éster, pois sugere um bom comportamento de lubrificação [5, 15]. Experimentos relatam que no caso da retificação, uma vantagem da mínima quantidade de lubrificante é que não aparecem as tensões residuais causadas por grandes gradientes de temperaturas, sendo isto especialmente importante no caso de materiais de corte frágeis [14]. Há várias vantagens devido à aplicação 
deste método. A névoa e o vapor, que são nocivos à saúde do trabalhador são reduzidos e o ajuste da mistura é muito fácil de ser controlada. Outras vantagens do MQL são: o barateamento na limpeza da peça final e a capacidade de visualização do processo, já que o local da usinagem não é inundado pelo fluido de corte como na técnica de refrigeração convencional [16]. Young [3] cita a mínima quantidade de lubrificação como uma das alternativas de um processo mais limpo menos prejudicial para o meio ambiente.

No Brasil vem crescendo o número de empresas com certificados ISO 14001, norma que tem sido adotada por organizações de diversos países como base para seu sistema de gestão ambiental, demonstrando uma tendência positiva à adoção desse tipo de sistema de gestão. Uma das grandes dificuldades do emprego da técnica de MQL na retificação é que o calor introduzido na peça no processo de retificação é superior quando comparado com as operações de usinagem com geometria definida, já que a geometria do grão abrasivo geralmente apresenta ângulo de cisalhamento negativo requerendo maior força de atrito na interação [17].

\section{A técnica da refrigeração otimizada}

A técnica da lubri-refrigeração otimizada consiste na utilização de um bocal otimizado, diferente dos bocais convencionais, e de outros acoplamentos a fim de proporcionar uma nova forma de aplicação de fluido de corte na região de interface entre peça e ferramenta. Existem alguns fatores que afetam diretamente a eficiência da aplicação do fluido de corte, incluindo-se o tipo e a velocidade do fluido utilizado, o posicionamento do bocal, o ângulo de abertura do bocal, o projeto do bocal, a utilização de um dispositivo para quebrar a barreira de ar envolta do rebolo e o tamanho dos grãos abrasivos do rebolo [18]. A aplicação de fluidos de corte é pouco eficiente nos métodos convencionais, especialmente sob condições de aplicação severas, já que a energia armazenada durante a sua aplicação não é suficiente para vencer a força centrífuga do rebolo ou penetrar na barreira de ar que o circunda o mesmo em movimento [19]. A otimização do processo de retificação implica não só na adoção do tipo mais efetivo de fluido de corte e sua mais adequada forma de aplicação. A qualidade da peça e o custo estão intimamente relacionados com a forma de aplicação do fluido de corte na região de interface rebolopeça. Um jato de fluido incidindo de forma direta sobre a região de corte é capaz de reduzir de forma significativa a temperatura nessa região, porém altas velocidades do jato de fluido são necessárias para a penetração do fluido de maneira efetiva, na região de corte. Também deve ser levada em consideração a abertura geométrica do bocal na entrada e saída do fluido, bem como as superfícies internas, sendo que se as mesmas forem de superfície geométrica côncava apresentarão um melhor efeito, pois estas tendem a aproximar as lâminas de fluido que se formam no interior do bocal (isto diminui o efeito de turbulência do fluido de corte). $\mathrm{O}$ bocal deve ser projetado de forma a causar a menor ocorrência de turbulência possível durante a saída do fluido
[20]. A velocidade com que o fluido penetra na região de corte deve compreender determinado valor, minimizando possíveis impactos fluido/ferramenta durante a penetração do fluido na região de corte [20]. Isto foi verificado quando a velocidade do fluido é igual à velocidade periférica do rebolo. Neste caso, o fluido tende a penetrar na região de corte com a mesma velocidade do grão abrasivo, não havendo assim interferências significativas por parte do fluido durante a remoção de material.

Os bocais devem ser projetados de forma a ocasionarem a menor ocorrência possível de turbulência durante a saída do fluido. Muita importância é atribuída ao raio de contração, que expressa a razão entre os diâmetros de entrada e saída do bocal, onde tal razão apresenta de maneira significativa a possibilidade da ocorrência de turbulência no bocal.

Alguns tópicos sobre o melhor design de construção do bocal foram relatados [2]: o acabamento da superfície do bocal deve ser liso e côncavo; o bocal deve ter bordas afiadas na saída; o bocal deve ter uma elevada relação de contração, da entrada à saída; quinas e mudanças bruscas no diâmetro do bocal devem ser evitadas; a performance não é muito sensível ao ângulo do bocal, contanto que o jato seja direcionado à região de corte; pode não haver necessidade de um bocal perfilado desde que haja um grande bocal redondo eficiente ou vários bocais redondos eficientes pequenos. Se um bocal retangular precisar ser usado, uma razão de aspecto de 5 para 8 é recomendada; uma tubulação reta colocada entre o condicionador de fluxo e a saída do bocal é necessária para provocar uma condição de velocidade e fluxo uniforme; quanto mais baixo o numero de Reynolds, mais eficiente é o jato; rebolos de alta porosidade apresentam uma maior taxa de remoção de material quando usados fluídos à base de água em relação aos óleos integrais. Entretanto, quando se usa rebolos densos, o contrário é verificado.

\section{MATERIAIS E MÉTODOS}

Os experimentos foram realizados na retificadora cilíndrica CNC, Sulmecânica RUAP 515 H, equipada com comando numérico computadorizado CNC. Os corpos de prova consistem de cilindros de uma alumina comercial, composta por $96 \%$ de óxido de alumínio e $4 \%$ de óxidos fundentes como $\mathrm{SiO}_{2}, \mathrm{CaO}$ e $\mathrm{MgO}$. A densidade aparente deste material é $3,7 \mathrm{~g} / \mathrm{cm}^{3}$. Foi utilizado um rebolo diamantado pois as peças a serem usinadas são de cerâmica [16]. O rebolo foi o de liga resinóide com dimensões $350 \mathrm{~mm}$ (diâmetro externo) x $15 \mathrm{~mm}$ (largura) x $5 \mathrm{~mm}$ (camada), diâmetro interno $127 \mathrm{~mm}$, dureza da liga $\mathrm{N}$, concentração 50 e tamanho de grão 126 mm (D 107 N 115 C50), Nikkon Ferramentas de Corte Ltda.. O fluido de corte foi uma emulsão de $5 \%$ em água do óleo semi-sintético Rocol 4847 Ultracut 370. Neste fluido de corte há, na sua composição, anticorrosivos, biocidas, fungicidas, alcalinizantes, antiespumantes, tensocitivos não iônicos, alcanolomidas, entre outros. Entretando, o fluido foi complementado com um anti espumante Rocol Ultragurd $\mathrm{AF}(\mathrm{S})$ e um bactericida. O equipamento de lubrificação 
otimizada consiste na utilização do mesmo fluido usado na refrigeração convencional, mas com a utilização de uma bomba mais potente, um medidor de vazão, e um bocal de metal soldado projetado especialmente para este fim. O equipamento para a aplicação da mínima quantidade de lubrificante é o baseado no principio de pressão, o qual o refrigerante é bombeado através de uma tubulação distinta da do ar comprimido [5]. Somente no bocal este refrigerante é misturado ao fluxo de ar e, então direcionado a interface de contato peça-ferramenta. $\mathrm{O}$ aplicador utilizado foi $\mathrm{o}$ ITW Accu-lube 79053D de micro-lubrificação, ITW Chem. Products Ltd.. Esse equipamento usa um sistema pulsante de fornecimento do óleo e permite a regulagem da vazão de ar comprimido e lubrificante de maneiras separadas. A vazão de ar comprimido é monitorada com auxílio de um medidor de vazão do tipo turbina modelo SVTG12/12BA4A44BS, Contech e calibrado a $8 \mathrm{Kgf} / \mathrm{cm}^{2}$. Para cada ensaio foram utilizados 13 corpos de prova. Foram utilizadas 3 espessuras equivalentes de corte distintas para cada tipo de refrigeração. Os valores de rugosidade foram obtidos para todos os ensaios. Para cada ensaio, a evolução da rugosidade foi obtida com a medição de 5 pontos do ensaio (peças 1, 4, 7, 10 e 13). Para cada peça, 5 medições em posições diferentes foram feitas a fim de se obter o desvio padrão. A captação da rugosidade superficial foi obtida através de um dos sistemas mais usados atualmente, o sistema mecânico [6], com um rugosímetro Surtronic 3+ Taylor Hobson, para a medição direta do parâmetro Ra. Os valores de erro e circularidade foram obtidos para todos os ensaios. Para cada ensaio, a evolução da do erro de circularidade foi obtida com a medição de 5 pontos do ensaio (peças 1, 4, 7, 10 e 13). Para cada peça, 5 medições em posições diferentes foram feitas, a fim de se obter o desvio padrão desta medição. As medições dos desvios de circularidade foram realizadas em uma máquina específica para controle de tolerâncias geométricas Tayrond 31c Taylor Hobson.

As análises de microestrutura por microscopia eletrônica de varredura foram realizadas por terceiros, necessitando apenas de uma devida preparação dos corpos-de-prova, incluindo o corte e a fixação dos corpos em uma resina e limpeza para a realização da análise.

$\mathrm{O}$ desgaste diametral do rebolo foi medido a fim de se obter a relação G. A obtenção da relação G se deu por meio da medição do desgaste do rebolo com cálculos de volume desgastado de material. O desgaste do rebolo foi possível de ser medido devido a não utilização da largura total do rebolo, onde a largura do rebolo utilizável era de $15 \mathrm{~mm}$ e a largura da peça $4 \mathrm{~mm}$. Desta forma o ressalto produzido no rebolo após o ensaio possibilitou a marcação do desgaste em um corpo de prova cilíndrico. A medição do desgaste foi feita utilizando-se um aparelho de deslocamento TESA digital TT10, com precisão de $1 \mu \mathrm{m}$. Para os ensaios foram estabelecidos as seguintes condições de usinagem: velocidade de mergulho $\left(v_{f}\right) 1 \mathrm{~mm} / \mathrm{min}$, velocidade de corte $\left(v_{s}\right) 30 \mathrm{~m} / \mathrm{s}$, rotação da peça $\left(\omega_{w}\right) 204 \mathrm{rpm}$, penetração do rebolo na peça $(a) 0,1 \mathrm{~mm}$, tempo de centelhamento $\left(t_{s}\right) 5$ $\mathrm{s}$, largura de retificação $4 \mathrm{~mm}$, profundidade de dressagem $\left(a_{d}\right) 0,02 \mathrm{~mm}$, vazão do fluido de corte na refrigeração convencional $22 \mathrm{~L} / \mathrm{min}$, vazão do fluido de corte no MQL $100 \mathrm{~mL} / \mathrm{h}$, pressão do ar no MQL 8 bar, velocidade de saída do ar $30 \mathrm{~m} / \mathrm{s}$ no bocal, velocidade de saída do fluido de corte na refrigeração otimizada $30 \mathrm{~m} / \mathrm{s}$. As três velocidades de avanços escolhidas foram: $0,75 \mathrm{~mm} / \mathrm{min}, 1 \mathrm{~mm} / \mathrm{min}$ e 1,25 $\mathrm{mm} / \mathrm{min}$. Desse modo, de acordo com a equação A, as três espessuras equivalentes de corte, denominadas $h_{e q 1}, h_{\text {eq } 2} e h_{e q 3}$ foram: $h_{e q 1}=0,0707 \mu \mathrm{m}, h_{e q 2}=0,094 \mu \mathrm{m}$ e $h_{e q 3}=0,118 \mu \mathrm{m}$.

\section{RESULTADOS E DISCUSSÃO}

Nesta seção serão apresentados os resultados, para cada condição de retificação realizada, das variáveis de saída: desgaste diametral e integridade superficial. Para a análise da integridade superficial avaliou-se a microestrutura por meio do MEV, o erro de circularidade e rugosidade. Ressalta-se que para as variáveis analisadas, mediante a construção de figuras de barra, calcularam-se os respectivos desvios padrões, os quais foram inseridos juntamente com os valores médios reais das três repetições executadas.

\section{Relação $G$}

A Fig. 5 mostra os resultados da relação $\mathrm{G}$ obtidas para os 3 tipos de lubrificação e $h_{e q}$.

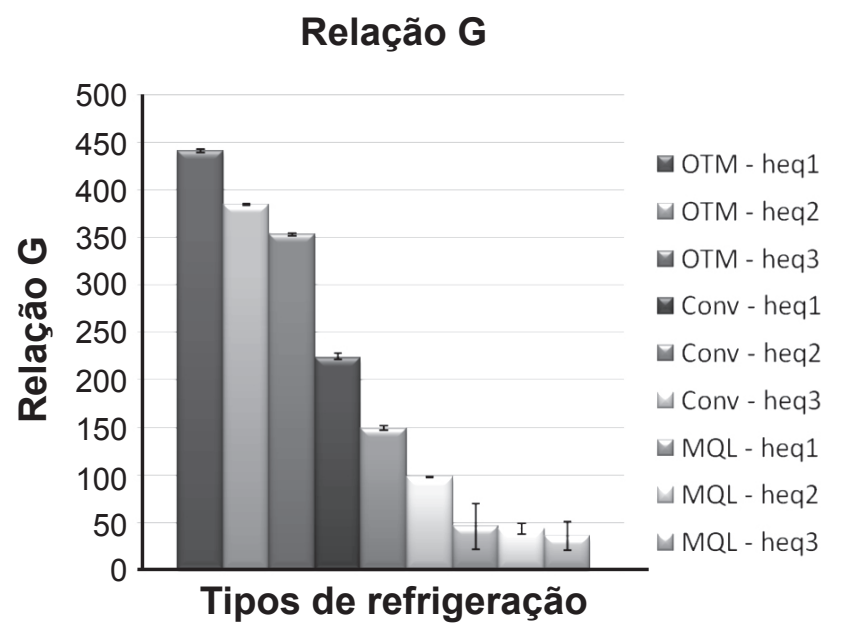

Figura 5: Relação G para os 3 tipo de lubrificação e $h_{e q}$. [Figure 5: G ratio for the 3 types of cooling and $\left.h_{\text {eq }}\right]^{\text {eq }}$

Os maiores valores obtidos para a relação $G$ foram para a refrigeração otimizada, seguida pela refrigeração convencional, depois para a técnica do MQL. Um dos possíveis causadores destes resultados é a menor dissipação térmica da região de corte provocada pela técnica do MQL, que faz principalmente o ligante perder sua resistência, fazendo o rebolo se desgastar mais. Analogamente, como na refrigeração otimizada a dissipação térmica é maior dentre os três casos, o ligante não perde sua resistência, fazendo o rebolo não se desgastar, o que aumenta a relação G. Pode-se notar que para a técnica da refrigeração otimizada e refrigeração 
convencional, a espessura equivalente de corte é um grande fator influenciador no desgaste do rebolo, conseqüentemente na relação G. Analisando o gráfico, pode-se notar que quanto maior a espessura equivalente de corte, maior o desgaste do rebolo, conseqüentemente, menor é a relação G. Para a técnica do MQL a espessura equivalente de corte não influenciou efetivamente na relação G. Isso pode ser explicado por outros fatores que provavelmente predominaram para o desgaste do rebolo, como, por exemplo, a menor dissipação térmica na zona de corte, o que fez a influência da espessura equivalente de corte se tornar praticamente imperceptível a níveis de resultados. Além disso, há um agravante na refrigeração com MQL, o qual há a formação de uma "borra" de cavaco com óleo que a força centrífuga do rebolo não consegue eliminar. Ela entope os poros do rebolo e prejudica a sua ação de corte. Esta provoca um desgaste excessivo do rebolo, o que projeta no seu aumento do desgaste, diminuindo relação G para esta técnica como um todo. Para a técnica da refrigeração otimizada, obteve-se, em geral, um aumento significativo da relação $\mathrm{G}$, sendo que a para a condição mais branda, $h_{e q 1}$, obteve-se uma melhora de quase $200 \%$ em comparação a melhor condição da refrigeração convencional. Também pode-se notar a influencia da espessura equivalente de corte pela figura. Quanto maior a espessura equivalente de corte, maior o desgaste do rebolo, conseqüentemente menor a relação $\mathrm{G}$.

\section{Rugosidade}

A Fig. 6 apresenta os resultados para a rugosidade média Ra referente à comparação entre as condições de lubri-refrigeração convencional, a técnica da refrigeração otimizada e a técnica da MQL.

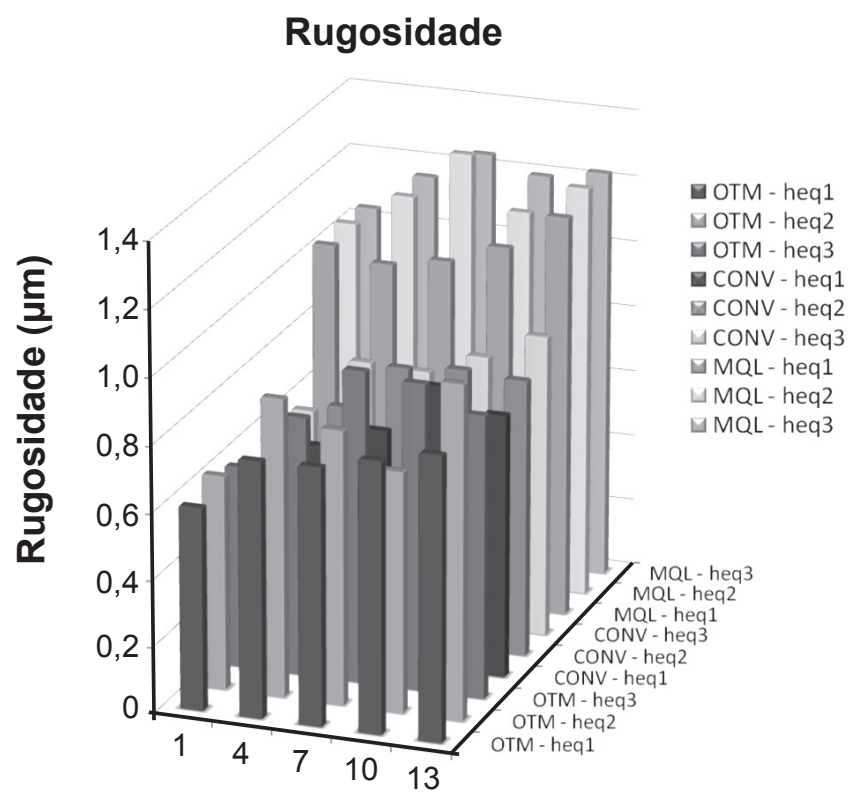

Número de peças

Figura 6: Rugosidade para os 3 tipos de refrigeração. [Figure 6: Roughness for the 3 types of cooling.]
Os valores de rugosidade foram menores para a lubrirefrigeração convencional e otimizada em comparação da técnica do MQL, possivelmente provocada pela melhor remoção de cavaco da zona de corte feita pela refrigeração convencional. No caso da refrigeração com a técnica do MQL, é formada uma "borra" de fluido com cavaco de difícil remoção, que mesmo ar comprimido a altas velocidades tem dificuldades de retirar. Esta borra de cavaco remanescente na zona de corte afeta consideravelmente os valores de rugosidade da peça.

As Figs. 7, 8 e 9 representam valores de rugosidade analisadas separadamente para cada caso de espessura equivalente de corte.

As técnicas da refrigeração otimizada e convencional

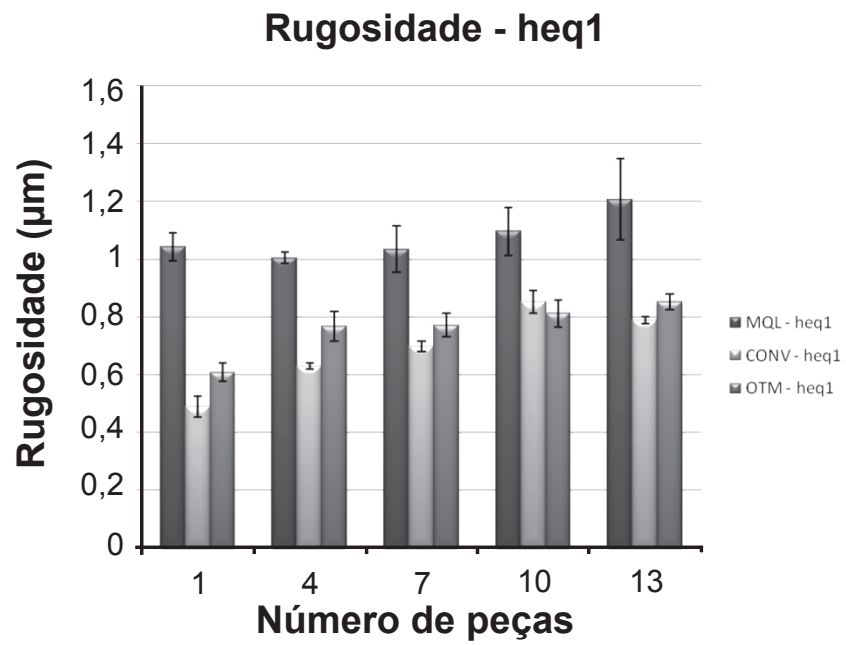

Figura 7: Evolução da rugosidade para os 3 métodos de refrigeração para $h_{\text {eql }}$.

[Figure 7: Evolution of roughness for the 3 types of cooling for $\left.h_{\text {eql }}.\right]$

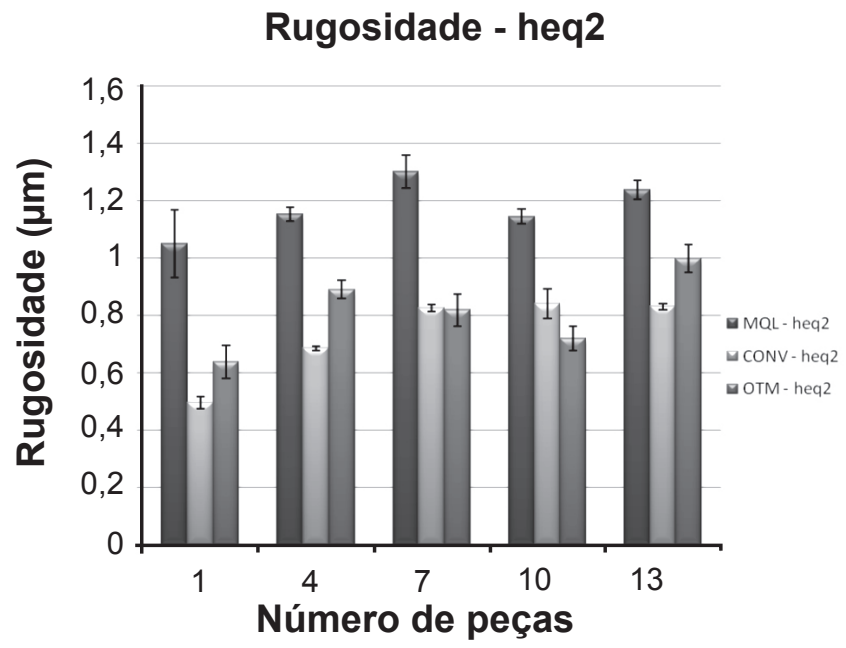

Figura 8: Evolução da rugosidade para os 3 métodos de refrigeração para $h_{e q 2}$.

[Figure 8: Evolution of roughness for the 3 types of cooling for $\left.h_{e q 2}.\right]$ 


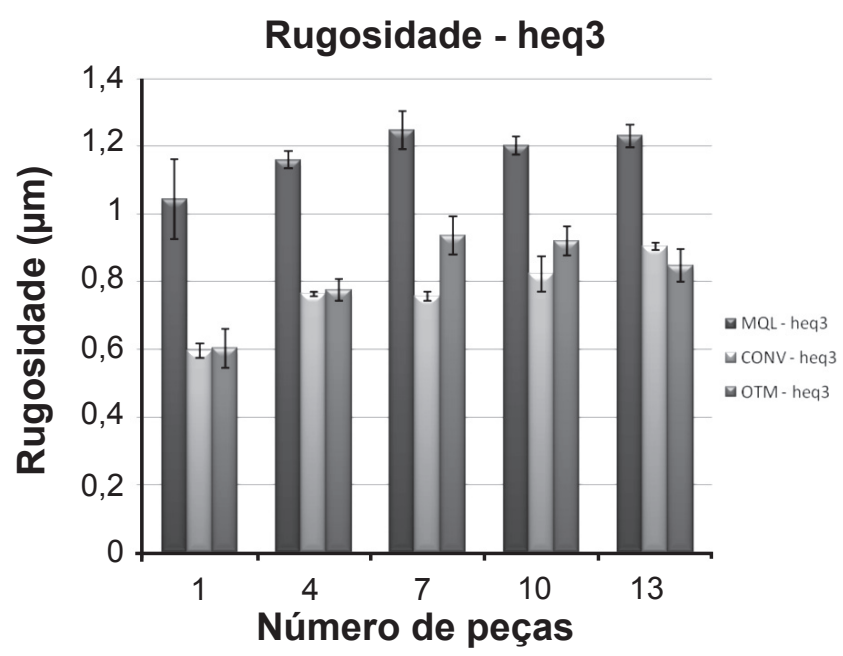

Figura 9: Evolução da rugosidade para os 3 métodos de refrigeração para $h_{e q 3}$.

[Figure 9: Evolution of roughness for the 3 types of cooling for $\left.h_{e q 3}.\right]$

apresentaram melhores resultados em relação à técnica MQL. Pode-se verificar também que não houve diferenças estatísticas entre a técnica da refrigeração otimizada e refrigeração convencional em muitos dos ciclos analisados. Nota-se para todos os casos, que a rugosidade aumenta ao longo do ensaio, sofre uma pequena queda, e logo após aumenta de novo. Isso se deve ao fato do auto-afiamento dos grãos abravisos, que vão perdendo suas microarestas de corte, proporcionando um corte mais severo, ocasionando um aumento de rugosidade, mas que logo são auto-avivados pelo processo de trinca dos grãos, ou separação dos grãos gastos do ligante.

\section{Circularidade}

São apresentadas 3 análises comparativas, a Fig. 10 para $h_{\text {eql }}$, a Fig. 11 para $h_{\text {eq } 2}$ e a Fig. 12 para $h_{\text {eq } 3}$. Comparando

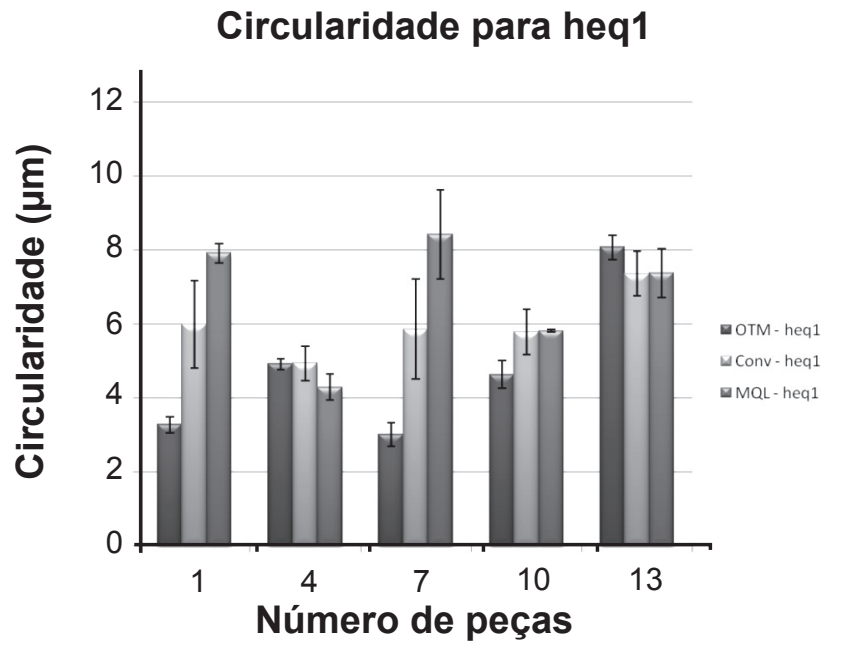

Figura 10: Evolução do erro de circularidade para os 3 métodos de refrigeração para $h_{\text {eq1 }}$.

[Figure 10: Evolution of circularity error for the 3 types of cooling for $\left.h_{\text {eql }}.\right]$

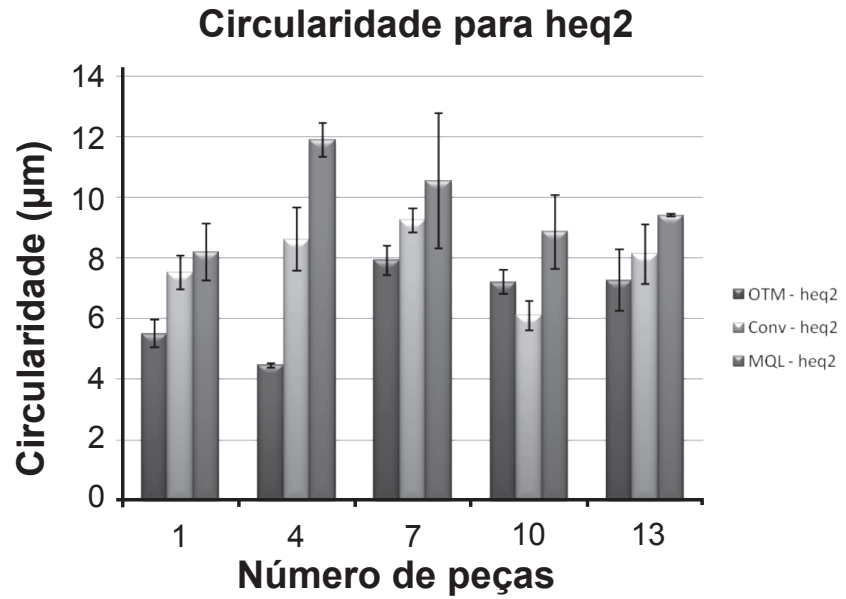

Figura 11: Evolução do erro de circularidade para os 3 métodos de refrigeração para $h_{e q 2}$.

[Figure 11: Evolution of circularity error for the 3 types of cooling for $\left.h_{\text {eq2 }}.\right]$

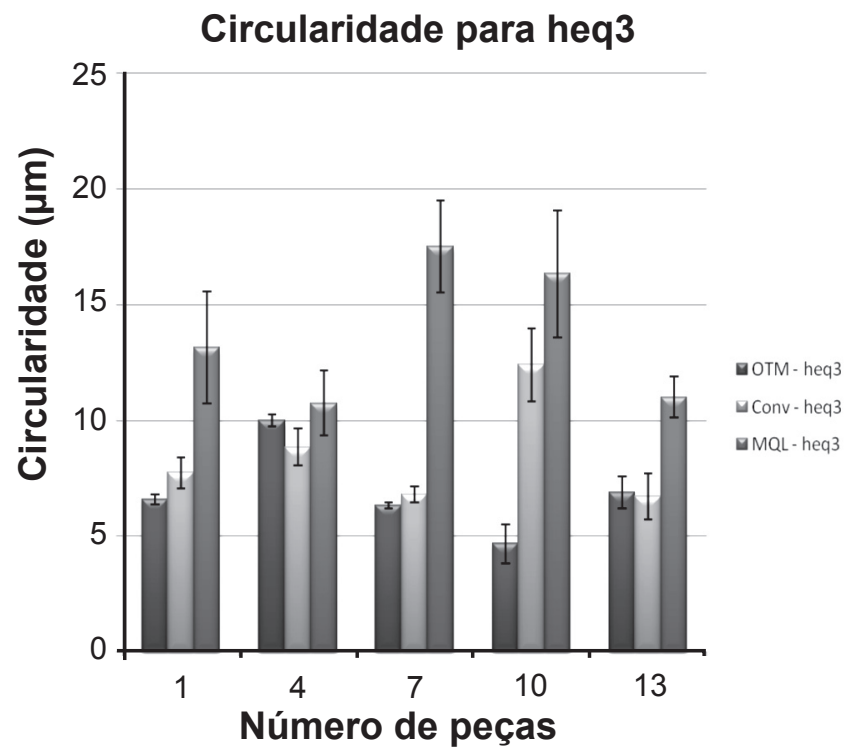

Figura 12: Evolução do erro de circularidade para os 3 métodos de refrigeração para $h_{e q 3}$.

[Figure 12: Evolution of circularity error for the 3 types of cooling for $\left.h_{\text {eq. }}.\right]$

a refrigeração convencional, a lubrificação com MQL e a técnica da refrigeração otimizada. Os dados são os valores das médias dos 3 ensaios de repetibilidade juntamente com os respectivos desvios padrões.

Nos pontos 1,7 e 10 a refrigeração otimizada apresentou estatisticamente melhores resultados. No ponto da peça 1, houve realmente a diferença entre as refrigerações, sendo a técnica da refrigeração otimizada a que obteve melhores resultados, seguida da técnica da refrigeração convencional, logo após a técnica do MQL. De modo geral, há uma tendência de melhores resultados para a refrigeração otimizada, seguida da refrigeração convencional e logo após da técnica do MQL, porém, estatisticamente, não é se é possível fazer esta distinção em todos os pontos, somente em alguns pontos. 
Apenas no término da peça 4 pode-se inferir estatisticamente a tendência da refrigeração otimizada como a refrigeração que obteve melhores resultados dentre os três métodos de refrigeração, seguida pela refrigeração convencional, logo após a técnica do MQL. No fim do ciclo de retificação da peça 1 , pode-se inferir que a refrigeração otimizada obteve melhores resultados comparado com os outros dois métodos de refrigeração. Nos outros casos, há apenas a tendência da média dos valores de circularidade obtida, não sendo possível afirmar que esta tendência é real devido os respectivos desvios padrão obtidos não mostrarem uma visível diferença no gráfico.

Para a situação mais severa $h_{\text {eq3 }}$, a refrigeração convencional e a refrigeração otimizada se mostraram melhores no final do ciclo de retificação da peça $1,7,10$, comparada com a técnica da refrigeração com MQL, sendo que nestes casos, a refrigeração otimizada se mostrou estatisticamente melhor dentre os três métodos de refrigeração. A técnica de refrigeração com MQL não apresentou diferenças de erros de circularidade significativos no que se diz respeito às condições mais brandas $\left(h_{\text {eq } 1} \mathrm{e}\right.$ $\left.h_{\text {eq2 }}\right)$. Para a condição mais severa $\left(h_{\text {eq3 }}\right)$, somente até o ciclo de retificação da peça 4 a técnica do MQL se mostra sem diferenças significativas.

\section{Microscopia eletrônica de varredura}

A Fig. 13 representa os resultados obtidos de microscopia eletrônica de varredura para as condições de lubri-refrigeração convencional com espessuras equivalente de corte respectivamente de $h_{e q 1}, h_{e q 2}, h_{e q 3}$.

$\mathrm{Na}$ refrigeração convencional o modo frágil de remoção do material predominou no processo, caracterizado microcrateras parte da superfície retificada. Há uma tendência ao modo dúctil de remoção à medida que se aumenta a espessura equivalente de corte, proporcionando menores crateras e uma melhoria no acabamento da peça.

A Fig. 14 mostra os resultados obtidos para as condições da técnica da refrigeração otimizada, com espessuras equivalente de corte respectivamente de $h_{e q 1}, h_{e q 2}, h_{e q 3}$.

$\mathrm{Na}$ refrigeração otimizada, assim como na refrigeração convencional, o modo frágil de remoção do material predominou no processo. Também há uma tendência ao modo dúctil de remoção a medida que se aumenta a espessura equivalente de corte, proporcionando uma melhoria no acabamento da peça.

A Fig. 15 mostra os resultados obtidos para as condições de lubrificação com a técnica do MQL, com espessuras equivalente de corte respectivamente de $h_{e q 1}, h_{e q 2} e h_{e q 3}$.
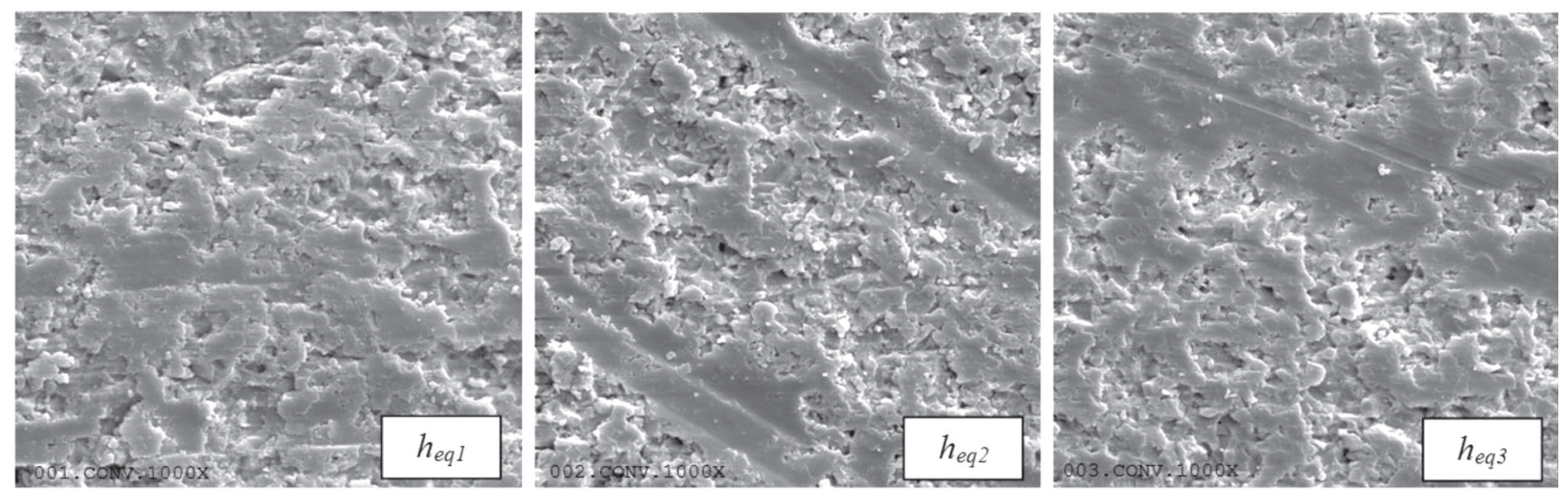

Figura 13: Micrografias obtidas por microscopia eletrônica de varredura para a refrigeração convencional para $h_{e q 1}, h_{e q 2} e h_{e q 3^{*}}$. [Figure 13: SEM micrographs for conventional cooling for $h_{\text {eq } 1}, h_{\text {eq } 2}$ and $h_{\text {eq } 3}$ ]
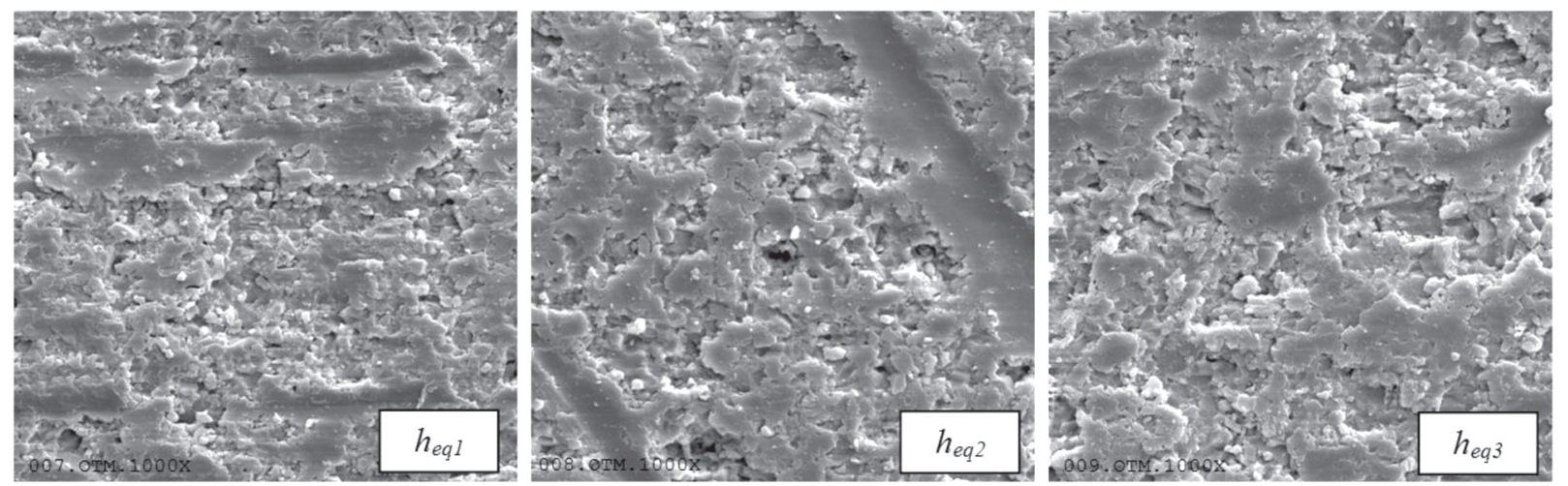

Figura 14: Micrografias obtidas por microscopia eletrônica de varredura para a refrigeração otimizada para $h_{e q 1}, h_{e q 2} e h_{e q 3}$.

[Figure 14: SEM micrographs for optimized cooling for $h_{\text {eq } 1}, h_{\text {eq2 }}$ and $h_{\text {eq3 }}$.] 

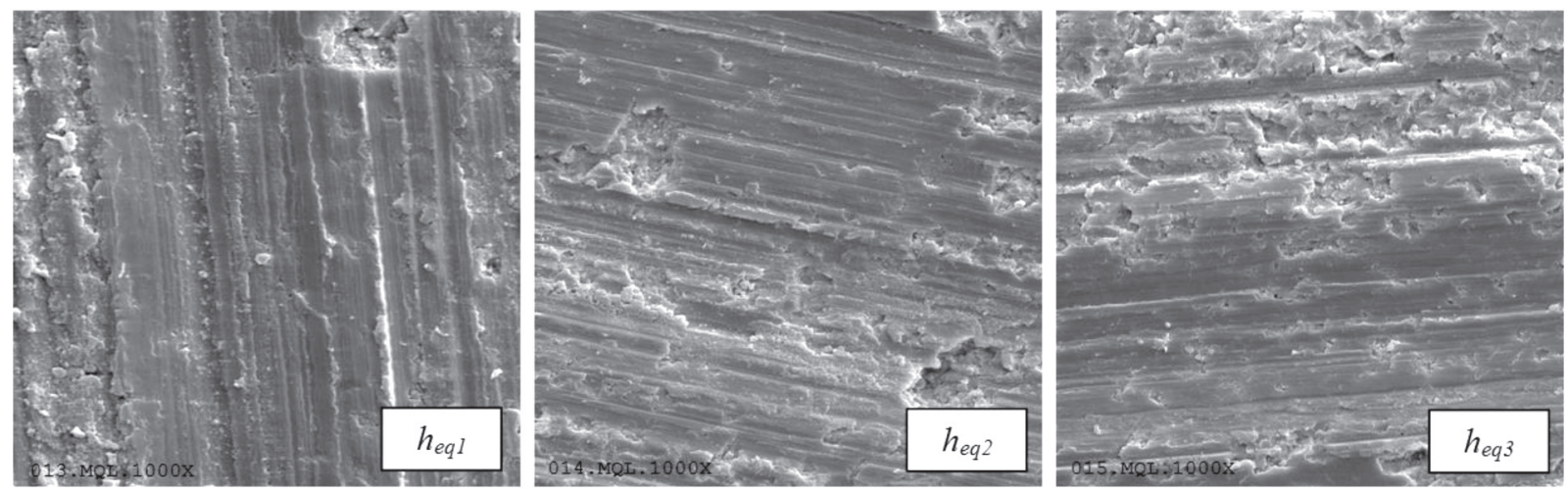

Figura 15: Micrografias obtidas com a microscopia eletrônica de varredura para o MQL para $h_{e q 1}, h_{e q 2} e h_{e q 3}$.

[Figure 15: SEM micrfographs for MQL for $h_{\text {eq } 1}, h_{\text {eq } 2}$ and $h_{\text {eq } 3}$.]

O modo de remoção predominante dos corpos de prova usinados utilizando a técnica do MQL foi o modo de remoção dúctil do material, o que proporciona ótimas condições de acabamento superficial no que diz respeito à resistência do material devido a presença reduzida de microtrincas, agente concentradores de tensão. Analisando as fotografias, podese observar que enquanto menor a espessura equivalente de corte, mais dúctil é o processo de remoção do material. A melhor caracterização da superfície da peça retificada com a refrigeração utilizando a técnica do MQL em relação à peça retificada com a refrigeração convencional pode ser explicada pelo maior poder lubrificante do óleo utilizado na técnica do MQL em comparação ao fluido de corte emulsificado utilizado na refrigeração convencional.

\section{CONCLUSÕES}

A refrigeração pela técnica da refrigeração otimizada é a que garante melhores resultados, tanto em acabamento da peça, quanto economia de ferramenta de usinagem (rebolo). A técnica do MQL demonstrou ser viável como uma alternativa para a substituição da lubri-refrigeração convencional para alguns casos de usinagem não implica em tolerâncias maiores que as encontradas neste trabalho. A condição que apresentou os melhores resultados foi de menor espessura equivalente de corte, $h_{e q 1}$ (velocidade de avanço de $0,75 \mathrm{~mm} / \mathrm{min}$ ), tanto para a refrigeração otimizada quanto para a técnica do MQL. Com relação à rugosidade a lubri-refrigeração convencional e otimizada não obtiveram diferenças significativas. A técnica do MQL apresentou valores relativamente maiores, porém, os valores obtidos principalmente com o $h_{e q 1}$, (velocidade de avanço a $0,75 \mathrm{~mm} / \mathrm{min}$ ) foram satisfatórios no processo de retificação cilíndrica externa de cerâmicas com rebolos diamantados. Analisando a integridade superficial das peças retificadas com a técnica do MQL por meio de microscopia eletrônica de varredura, observou-se que esta apresentou melhores resultados de superfície do corpo de prova em relação aos corpos de prova retificados com a refrigeração convencional. Em relação ao erro de circularidade, não ocorreram diferenças significativas entre a lubri-refrigeração convencional, otimizada e a condição de MQL com o $h_{e q 1}$ e $h_{e q 2}$ (velocidades de avanço de $0,75 \mathrm{~mm} / \mathrm{min}$ e $1 \mathrm{~mm} / \mathrm{min}$ ). Com relação a variável relação $\mathrm{G}$, a refrigeração otimizada obteve valores relativamente maiores em relação as duas outras técnicas de refrigeração estudadas. A técnica do MQL por sua vez, apresentou valores relativamente menores em comparado com as outras técnicas de refrigeração.

\section{AGRADECIMENTOS}

Ao CNPq pelas bolsas de iniciação científica, à FAPESP pelos recursos financeiros disponibilizados para esta pesquisa e pelas bolsas de iniciação científica.

\section{REFERÊNCIAS}

[1] G. M. Bustamante, J. C. Bressiani, Tile \& Brick Int. 16. (2000) 27.

[2] R. A. Irani, R. J. Bauer, A. Warkentin, Int. J. Machine Tools Manufact. 45 (2005) 1696.

[3] P. Young, G. Byrne, M. Cottere, Int. J. Adv. Manufact. Technol. 13 (1997) 488.

[4] A. G. Mamalis, J. Kundrak, K. Gyani, M. Horvath, Int. J. Adv. Manufact. Technol. 20 (2002) 255.

[5] K. Ramesh, S. H. Yeo, S. Gowri, L. Zhoul, Int. J. Adv. Manufact. Technol. 17 (2001) 87.

[6] I. Marinescu, H. K. Tönshoff, I. Inasaki, Handbook of Ceramic Grinding and Polishing, Noyes Publ, New Jersey, EUA (1998).

[7] S. Malkin, T. W. Hwang, Annals CIRP 45, 2 (1996) 569.

[8] T. W. Liao, G. Sathyanarayanan, L. J. Plebani, M. U. Thomas, K. Li, Int. J. Mechanisms Sci. 9 (1995) 1035.

[9] J. F. G. Oliveira, Análise da ação do macroefeito de dressagem de rebolos no desempenho do processo de retificação, Tese Dr., USP, S. Carlos, SP (1988).

[10] W. Graf, Cylindrical Grinding, Copyright WST Winterthur Schleiftechnik AG, Suiça (2004) 87.

[11] S. Malkin, Grinding Technology: Theory and Aplications of Machining with Abrasives, Ellis Horwood Ltd., Chichester (1989).

[12] A. E. Diniz, F. C. Marcondes, N. L. Coppini, Tecnologia da usinagem dos materiais, $2^{\text {a }}$ Ed., Artiliber Ed Ltda., Campinas, SP (2000) 225. 
[13] T. Obikawa, Y. Kamata, J. Shinozuka, Int. J. Machine Tools \& Manufact. 46 (2006) 1854.

[14] U. Heisel, M. Lutz, D. Spath, R. Wassmer, U. Walter, Rev. Máquinas Metais 385 (1998) 22.

[15] F. Klocke, G. Eisenblätter, Annals CIRP 46, 2 (1997) 519.

[16] A. Attanasio, M. Gelfi, C. Giardini, C. Remino, Wear 260 (2006) 333.

[17] F. Klocke, T. Beck, G. Eisenblätter, R. Fritsch, D. Lung,
M. Pöhls, Inst. Machine Tools and Production Eng., Univ. Technology (2001)

[18] J. D. Campbell, $1^{\text {st }}$ Int. Machining and Grinding Conf, Soc. Manufacturing Eng., Deabornn, MI, EUA 12 (1995) 895.

[19] C. Guo, S. Malkin, Asme J. Eng. for Industry 104 (1992) 427.

[20] J. A. Webster, Supergrind, Univ. Connecticut, EUA (1995) 205.

(Rec.01/02/2010, Rev. 18/02/2010, Ac. 26/12/2010) 